\title{
LÓGICA FORMAL, LÓGICA DIALÉTICA: QUESTÃO DE MÉTODO EM GEOGRAFIA
}

\author{
Everaldo Batista da Costa \\ Coordenador do GECIPA, Professor doutor do Depto de Geografia \\ UnB \\ everaldocosta@unb.br \\ Rafael Fabrício de Oliveira \\ Integrante do GECIPA,Discente do PPGG \\ $\mathrm{UnB}$ \\ Renan Amabile Boscariol \\ Integrante do GECIPA,Discente do PPGG \\ $\mathrm{UnB}$ \\ Carolina Starling Souza \\ Integrante do GECIPA,Discente do PPGG \\ $\mathrm{UnB}$ \\ Rúbia de Paula Rúbio \\ Integrante do GECIPA,Discente do PPGG \\ $\mathrm{UnB}$
}

O presente trabalho deseja ser mais que uma resenha crítica, mas um exercício e chamado ao debate sobre método em Geografia. Também quer representar resistência à lógica formal imposta pelo atual produtivismo acadêmico, ao fazer alusão interpretativa de uma única obra, mas desenvolvida por cerca de um ano (2013-2014). Valoriza a reflexão conjunta, amadurecimento recíproco de professor e alunos, no Grupo de Pesquisas Cidades e Patrimonialização, da Universidade de Brasília. Esses trabalhos periódicos reflexivos tiveram início em 2011 e Lógica Formal / Lógica Dialética, de Henri Lefebvre, é a segunda obra avaliada, de uma série que se pretende no decorrer dos anos, ou seja, este trabalho guarda um projeto acadêmico de reconhecimento dos métodos dialético, existencialista e fenomenológico, na Geografia.

O livro que ora debruçamos, apesar de escrito entre 1946-1947, é extremamente atual à Geografia, do ponto de vista da abordagem metódica, por tratar das nuanças do idealismo hegeliano, do materialismo histórico e da dialética. Lefebvre tinha a intenção de publicar oito livros (um Tratado de Materialismo Dialético), saiu apenas este 
volume, o qual sofreu as mais duras críticas. Era acusado de não contribuir para a elaboração de uma lógica proletária, revolucionária, socialista francesa, ao focar na demonstração da lógica inerente ao mundo da mercadoria e seu entendimento. Não pediam uma análise da coesão interna, malgrado as contradições da sociedade burguesa, quando os proletários franceses exigiam que uma lógica, enquanto tal, apresentasse um caráter de classe (a proletária). O livro ensina o pensamento dialético, segundo uma ordem didática e teórica, em quatro densos capítulos: Teoria do Conhecimento; Os movimentos do pensamento; Lógica formal; Lógica Concreta (dialética).

Henri Lefebvre abre a obra com questões relativas à teoria do conhecimento. Trata a conceituação do conhecimento como fato, que se realiza desde a vida prática mais imediata e simples, através do conhecimento dos objetos circundantes. $\mathrm{O}$ conhecimento como fato decorre da interação dialética sujeito-objeto, e apresenta três características gerais: o conhecimento é prático, através da experiência o ser humano estabelece o primeiro contato com a realidade objetiva; o conhecimento é social, pois através da vida de existência estabelecem-se contatos objetivos que permitem relações entre pessoas e com as coisas; por fim, o conhecimento tem caráter histórico, pois resulta do acúmulo de ideias e pensamentos desenvolvidos por indivíduos, na longa duração da história social.

No cerne desta discussão, Lefebvre se volta para o problema do conhecimento gerado pela metafísica, quando esta, por meio da análise, separa os elementos do conhecimento (sujeito e objeto) e toma a realidade a partir de um deles. Esclarece o autor que os metafísicos idealistas, ao confundirem conhecimento e ideia, vendo-o como algo apriorístico à experiência humana, tornam absoluta uma pequena parte deste conhecimento. As doutrinas idealistas defendem a existência da consciência vinculada à ideia. Esta não só existe separada da natureza e do homem real, mas produz um mundo imaginário e baseado em um pensamento misterioso que, no limite, exige a existência de um divino, um deus metafísico, que seria fonte de toda a verdade. No extremo, tais idealistas negam completamente a existência material e concreta, confundem o mundo com a imagem do mundo e trazem a mente e a consciência como a única coisa existente de fato. A realidade material emerge como produto de sensações originadas em nossa consciência. Em contraponto à metafísica idealista, encontram-se alguns materialistas mecanicistas, que ao reagirem ao pensamento idealista, elevam o mundo concreto a 
níveis tão absurdos quanto estes. Tais pensadores chegam ao extremo de negar a própria consciência e o indivíduo, pois na busca da explicação concreta do funcionamento da realidade, generalizam a mecânica e a física dos corpos a todos os aspectos da realidade social; surge de tal pensamento uma metafísica materialista, pois também coloca de forma equivocada o problema do conhecimento, assegura Henri Lefebvre.

Neste materialismo metafísico, a consciência é confundida com mero reflexo de fatos objetivos (mecânicos); as ações dos seres humanos são comparadas às de simples autômatos. No limite, esta proposição metafísica do materialismo nega a existência objetiva da consciência e da ideia, substituindo o mundo metafísico idealista por um mundo mecanicista regido por leis gerais do movimento da matéria. A história humana apareceria, assim, como um conjunto de causas e efeitos que seriam consequências de leis gerais e absolutas que determinariam as ações e a vida, considera Henri Lefebvre.

Do ponto de vista filosófico, a oposição entre materialismo e idealismo seriam absolutas. Todavia, Lefebvre diz que, se examinarmos a questão do conhecimento e o pensamento filosófico sob o ponto de vista da história das ideias, tais oposições deixam de ser absolutas e percebemos que a relação entre estas formas de pensamento penetram-se reciprocamente. $\mathrm{O}$ autor diferencia idealismo objetivo do idealismo dogmático. O idealismo objetivo, embora considere a predominância da consciência e da ideia, aceita a existência do mundo material fora da mente, o que é negado pelo idealista dogmático. Lefebvre ressalta a importância do idealismo objetivo para o desenvolvimento "dos instrumentos mais penetrantes do conhecimento". Os idealistas objetivos, segundo o autor, contribuíram mais para o entendimento do movimento e dos momentos do pensamento que os próprios materialistas, tarefa na qual se destacam Descartes e Hegel. Por outro lado, aponta como o materialismo mecanicista e atomista (vulgar) estabelece uma oposição a um verdadeiro materialismo dialético.

Fica clara a posição do autor quanto ao lugar da prática e do contexto histórico para a construção do conhecimento; critica o positivismo e o pensamento sociológico para demonstrar a concretude da relação entre prática e conhecimento. A crítica aos sociólogos se deve, pois, ao fato de que ao estudarem o funcionamento das sociedades, buscam o entendimento da dinâmica social como algo acima e fora do indivíduo. Ao positivismo, sua crítica recai à separação do trabalho intelectual, da teoria e da prática, e do cientista e do ser social. Propõe como superação destas limitações a lógica concreta 
ou dialética. Tal lógica considera não somente a realidade social em toda a sua dimensão histórica, mas a própria história do conhecimento, "a própria teoria do conhecimento como história da prática social". Segundo o autor, tal lógica é "o resultado vivo... de toda a experiência humana", em sua forma mais elaborada, vinculada a "uma concepção científica (racional) da história".

À Geografia, este primeiro capítulo contribui para o pensamento de sua teoria e conhecimento produzidos. Faz-nos pensar que o conhecimento geográfico objetivo também é poder sobre a natureza, em termos de exploração e mais conhecimento, em um ciclo permanente de domínio e pujança intelectual. Faz-nos pensar que a sociedade e o indivíduo aparecem, muitas das vezes, como abstrações, se lançadas ao nível do domínio da natureza, pela ânsia do conhecimento e da produção. Em suma, faz-nos questionar a objetividade da Geografia face ao seu conhecimento produzido, na dimensão do desenvolvimento humano, em caráter qualitativo e quantitativo, e na relação sujeito e objeto. Induz à interrogação: a que serve, de fato, a Geografia e mais, a universidade? (Antônio Carlos Robert Moraes afirma que o caráter público do conhecimento e da universidade deve se firmar pela sociedade e não pelas instituições ou Governo, quando a Geografia deve assumir a avaliação crítica de políticas espaciais).

No debate sobre Os movimentos do pensamento, segundo capítulo da obra, Henri Lefebvre mantém o propósito de desnudar o pensamento dialético e revela aspectos da dimensão do método. Defende o pensamento verdadeiro, considerado o próprio conhecimento, de maneira que "todo pensamento é movimento" projetado para o devir.

Em sua concepção, não há sentido somente estudar coisas do passado como se pertencessem só a este passado, pois, segundo ele, as coisas se projetam e se movimentam. Assim, uma noção grandemente percebida nesta obra, a propósito da dialética como método, é a necessidade de se conceber o objeto e o objetivo da pesquisa enquanto pertencentes a um processo (histórico, ou social, ou da natureza); objeto como delimitação necessária, objetivo como razão de ser do conhecimento. É reforçado o caráter momentâneo do conhecimento, e o esforço do pensamento leva a uma totalidade parcial dotada de erros também momentâneos, que integra algo maior e movente. Fica claro que o objeto do conhecimento está sempre em movimento e integra um todo que deve ser perseguido e apreendido enquanto tal e em dado espaço-tempo. 
Acerca do objeto do conhecimento, aparecem duas noções fundamentais na obra: a verdade absoluta e a verdade relativa. Henri Lefebvre destaca que todo esforço verdadeiro do pensar chegará sempre a verdades relativas, e estas, quanto mais profundas e densas, mais próximas da verdade absoluta. A este propósito da verdade absoluta, o autor destaca que se trataria de uma "totalidade infinita [de] verdades relativas em todos os graus, em todas as escalas". E, se for possível atingir o limite mais infinitamente longínquo, a totalidade do pensamento corresponderia à própria totalidade do universo. A ciência pautada na dialética, enquanto fundamentação teórica e metodológica, a priori, aproxima-se da verdade absoluta, ou seja, ao movimento pleno do processo de construção da totalidade histórico-social.

Em defesa da dialética, Henri Lefebvre contrargumenta com os princípios filosóficos da metafísica, do empirismo, da lógica e do positivismo, sobretudo. Este autor constrói uma teorização acerca do pensamento dialético, com ressalvas e ratificações percebidas nestas outras perspectivas filosóficas. Por exemplo, o princípio essencial da contradição é concebido de forma otimista, ou seja, como inspirador ao progresso do pensamento. Ao passo que a contradição pode ser percebida enquanto erro, se se pensar na construção de uma verdade sólida e intocável, a dialética vê a própria contradição que é também uma negação como caminho de análise. Negar uma coisa é promover movimento, e a coisa negada incluirá todo o princípio que fundamentava a existência da coisa anterior, só que o resultado é a coisa pensada, refletida, avançada. $\mathrm{E}$ é dessa forma que se dá o progresso cientifico, a tentativa de aproximar da verdade absoluta, o estar em movimento, o esforço verdadeiro do pensamento.

A operação que conduz ao movimento dialético do pensamento é a concepção relacional e simbiótica entre conhecido e desconhecido. Busca-se o desconhecido, através de um conhecido momentâneo. Admite-se o desconhecido enquanto movimento, enquanto devir, enquanto esforço necessário de pensamento. A busca concreta, que torna o conhecido também cada vez mais concreto, visa à verdade absoluta, que é o próprio desconhecimento. Para Lefebvre, tal busca se configura em valiosa indicação de pesquisa individual, que deve se respaldar na cooperação científica à construção do pensamento humano, que seria uma totalidade de conhecimento edificado por meio da razão, não negando o papel essencial da abstração. 
Seu segundo capítulo, então, reforça à Geografia o papel das periodizações, para aproximação à verdade absoluta. Cada momento de uma periodização (a qual aproxima o acontecer espaço-temporal) indica uma verdade relativa sobre o objeto, em um dado espaço-tempo ou momento espacial. Lembra à Geografia que o princípio da contradição e a negação vistas de forma otimistas podem inspirar o progresso do pensamento. Contudo, acreditamos que a crítica pela iluminação da contradição e da negação não pode permanecer abstrata ou negar, absolutamente, o mundo vivido, pelo contrário, entendemos que o momento simultâneo da contradição é a não contradição, a própria lógica da vida que segue, da existência geográfica ou de uma geografia da existência. Em estudo anterior, indagamos, "Se o marxismo vive da indestrutível unidade entre teoria e prática, ciência e fato, e, se cada análise marxista deve contemplar esta unidade, qual o propósito de uma Geografia Crítica que ignora as possibilidades de transformação espacial do presente, tanto por meio da negação radical do Estado, quanto pela refutação da eficácia mínima de seus instrumentos de ordenamento espacial?" (Costa; Suzuki, 2012, p. 122).

O terceiro capítulo revisa a Lógica formal, pelo propósito da obra: ensinar o pensamento dialético, didática e teoricamente. Em Lefebvre, a lógica formal antecede a lógica concreta como um dos momentos da razão. O autor assinala os elementos basilares deste sistema de pensamento: forma, formalismo, princípio da identidade, termo, estática e dinâmica do conceito, os juízos analíticos e sintéticos, raciocínio, inferência, silogismo, o ser e a ideia, além de situar, historicamente, seu desenvolvimento. Nesse sentido, explicita as principais diferenças na decomposição do pensar: pela lógica formal há redução estrita do conteúdo, que resulta num entendimento metafísico de formas sem suas qualidades e isolando o entendimento da realidade em fragmentos; já pela lógica dialética há apenas uma eliminação momentânea do conteúdo, que o autor considera como "negação dialética" e que permite captar suas qualidades captando-as em sua totalidade. Resulta que a lógica formal gera um saber tautológico, que não aceita a contradição e a imperfeição, além de reduzir aspectos da realidade em partes, num movimento abstrato, que não possui eficácia de retorno ao todo, enquanto que a lógica dialética não elimina parte do pensamento, apenas nega-a momentaneamente, retomando a sua totalidade pelo enlace entre forma e conteúdo. Ao apresentar o princípio da identidade (da não-contradição), 
revela toda fragilidade da lógica formal; mostra que a ausência do movimento não permite ao pensamento se libertar do imediato, das sensações e dos limites internos do conteúdo: este pensamento ao descrever não explica, fecha e isola os conceitos.

Lefebvre enaltece que, mesmo no caso da individualidade humana, com suas singularidades e particularidades, ela está envolta por traços universais, o que é relegado pela lógica formal; seus preceitos são de um nível inferior, só validados em certos limites. Tais enquadramentos são erigidos por um juízo, que na lógica formal se desenvolve por intermédio do verbo "ser", e que permite encontrar e revelar a sua própria contradição, do tipo $\mathrm{A}=\mathrm{B}$, pois a diferença provém do conteúdo e não da forma. Ao contrário do que se pode pensar, os elementos possuem relações e quando são separados não passam de "pura ficção lógica". Mesmo negando a contradição, o pensamento formal é obrigado a partir de bases prévias, gera proposições e criações, além de mediações no sentido de se obter suas próprias conclusões, afirma Lefebvre.

A lógica formal assenta-se em metodologias permeadas pela ambiciosa linguagem universal da álgebra, da matemática, ou criticamente: do simbolismo abstrato que não resolve problemas paradoxais, transformando-os simplesmente em espécies de axiomas. Para Lefebvre, a logística foi fecunda para manifestar justamente a necessidade do conteúdo, ainda que muitos se fechem pura e esterilmente na própria forma; mesmo estes ganham um sentido válido, embora limitado. A lógica formal ignora que os fenômenos fazem parte de um movimento dinâmico e permeado por transformações: contraposição entre o "ser" formal e genérico e o "ser" concreto e real. O papel da redução formal, portanto, deve ser transposto entre um e outro sentido incessantemente: "do ser abstrato ao ser concreto (conteúdo), para captá-lo; do ser concreto (conteúdo) ao ser abstrato, para analisa-lo”, assegura Lefebvre. Mesmo com a destruição do formalismo, a lógica formal não deve ser ignorada, pois se relaciona com toda história do conhecimento e mesmo com o pensamento concreto, que agrupa, unifica e sintetiza a razão, capturando momentos dispersos da história complexa.

Ao tratar das bases formais do pensamento, atacando-o criticamente e revelando a necessidade de sua superação, este terceiro capítulo da obra indica à Geografia a relação entre a forma e seu conteúdo, os objetos e as ações, o mundo da empiria matematizada como momento relevante de desvendamento de contradições espaciais. Essa reflexão filosófica de Lefebvre justifica o reconhecimento da lógica dialética que 
rege o mundo concreto, no fragmento do lugar. Chama a atenção para não isolarmos ou fecharmos os conceitos (especialmente, o espaço geográfico), pois estes são expressão abstrato-concreta da realidade. No limite, o mundo produzido é latência fecunda de uma vida espacial repleta de significados em trânsitos, o que nos faz valorizar, na Geografia, o potencial real da análise empírica enquanto momento da apreensão da totalidade ou da realidade espacial efetiva (questão que parece esquecida ou negligenciada pela ala radical da Geografia Crítica). Nesse aspecto, devemos recordar Armando Correa da Silva, ao dizer que a Geografia trata de problemas relacionados a três níveis da realidade: a) à natureza, incluindo o homem como espécie antropológica; b) à vida social, no sentido de que não existe um homo geographicus, abstrato, mas pessoas vivendo em e dando vida a sistemas sociais; c) às relações entre sociedade e natureza. A Geografia aparece, então, como o estudo da "organização" do espaço nesses três níveis.

Por fim, no último capítulo do livro, Henri Lefebvre apresenta as principais leis que fundamentam a lógica dialética; situa a lógica formal como um momento na busca do conhecimento que, se concentrado na forma e na abstração, acaba por deixar escapar a essência dos fenômenos e seu conteúdo, tornando-se pouco fértil na compreensão da realidade. Na lógica concreta, as leis presentes na realidade, como o movimento e as contradições, são leis do pensamento, que se torna consciente desses elementos e busca a unidade e a identidade presente em forças aparentemente opostas, na tentativa de superá-las em direção a um aprofundamento que leva a novo patamar no conhecimento.

O método dialético é sintetizado pelo autor a partir de leis como: a lei da interação universal, que considera que nada é isolado e que todos os fenômenos estão em relação com os demais; a lei do movimento que reintegra os fenômenos, conectando as ideias e identificando tendências; a lei da unidade dos contraditórios; a lei da transformação da quantidade em qualidade, que ressalta a importância das crises e conflitos; e a lei do desenvolvimento em espiral, que revela a necessidade de aprofundamento das contradições para que possam ser superadas. Todas essas leis são leis do movimento, que implica em continuidade e descontinuidade, aparecimento e choque de contradições, saltos qualitativos e superação. A partir dessas leis, são sugeridas regras do método dialético como: análise objetiva, apreensão do conjunto de conexões e seu movimento, busca da totalidade e união dos contraditórios, busca das tendências, análise das relações e transições, busca de aprofundamento do conhecimento 
a partir da passagem da essência ao fenômeno e do fenômeno à essência, e apreensão do conteúdo a partir das conexões e do movimento.

Na compreensão dialética, a separação e análise aparecem como momentos aos quais se seguem a síntese e a relação com a totalidade. Desse modo, a fragmentação, o reducionismo e o quantitativo são considerados etapas na direção de uma compreensão maior, a qual se faz a partir da retomada da síntese e da identificação das tendências, assegura Lefebvre. A lógica concreta se afirma, então, como uma possibilidade de ultrapassar a dicotomia teoria e prática, abstração e empirismo, ao considerá-los momentos complementares na busca pelo conhecimento.

Baseada nas leis da natureza, a razão dialética supera o pensamento formal e busca captar a unidade e a conexão entre pares aparentemente opostos, ao compreender as contradições como inerentes à vida, em permanente relação e movimento. Daí a crítica às análises de tendência mecanicista e o reconhecimento de que um organismo vivo se apresenta como um todo em si mesmo e em constante intercâmbio com o meio. Ao restituir os fenômenos em suas relações e movimentos, a ciência os considera inseridos no conjunto, na totalidade das interações que são próprias da natureza. A contradição mais evidente nos organismos é a vida e a morte; no auge do desenvolvimento de um ser vivo já se observa o início do declínio que traz a morte em si; vida e morte, pares complementares, apresentam-se, então, unidos.

Por fim, a análise de Lógica formal / lógica dialética, de Henri Lefebvre, pode indicar à Geografia a exigência de teorias a partir de leis universais, que se apresentem, eficaz, atual e potentemente, no pensamento e no real; exige superar o pensamento formal e fundamentar o conhecimento espacial e a observação da natureza apoderada, vista como dinâmica e repleta de contradições, ao ser tomada no viés social produtivo. Assim, é bom lembrar com Lefebvre, para tratar a Geografia como ciência e como existência que, entre o universal e o concreto, é impossível suprimir a mediação do particular; análise de casos, conceitos, relações por meio da experiência indicam o contato com o conteúdo em devir, a simultaneidade da quantidade-qualidade de todo objeto ou ser em espacialização ou espacialidade..

\section{Referência Bibliográfica}

COSTA, Everaldo B; SUZUKI, Júlio C. Materialismo histórico e existência: discurso geográfico e utopias. Revista Espaço e Geografia, vol. 15, nº 1, 2012, p. 115-147. 
LEFEBVRE, Henri. Lógica formal/lógica dialética. Rio de Janeiro: Civilzação Brasileira, 1975.

MORAES, Antônio C. R. Meio ambiente e ciências humanas. São Paulo: Annablume, 2005 .

SILVA, Armando C. A aparência, o ser e a forma (Geografia e Método). Revista GEOgraphia, Niterói, Ano II, nº 3, 2000, p. 7-25. 